\title{
Quem é negra, quem é branca, quem fala, quem pode falar: etnografia de mulheres negras em uma turma de formação de docentes
}

\author{
ALINE ADRIANA DE OLIVEIRA
}

UNIVERSIDADE FEDERAL DO PARANÁ (UFPR), CURITIBA/PR, BRASIL HTTPS://ORCID.ORG/OOOO-OOOI-6927-3865

CAROLINA DOS ANJOS DE BORBA

UNIVERSIDADE FEDERAL DO PARANÁ (UFPR), CURITIBA/PR, BRASIL HTTPS://ORCID.ORG/0000-0003-3690-94II

\section{Introdução}

Este artigo se propõe a refletir sobre estratégias, conflitos e legitimações em torno da questão racial que compuseram uma investigação etnográfica realizada entre outubro de 2018 e outubro de 2019, no âmbito da formação de docentes à Educação Básica. A pesquisa, para monografia de graduação em Ciências Sociais ${ }^{1}$, foi realizada em uma escola pública de Curitiba (PR), com uma turma de terceiro ano noturno do curso de magistério, ofertado de maneira integrada ao Ensino Médio, com cerca de 21 estudantes. Havia somente um aluno do sexo masculino, e as idades discentes variavam entre 17 e 30 anos.

Entre o início de outubro e o final de novembro de 2018, a entrada, a saída, os intervalos e as aulas dessa turma foram acompanhados, buscando observar como aparecia a questão em foco nos dis-

1 Monografia de graduação orientada pela Prof ${ }^{a} \operatorname{Dr}^{a}$ Carolina dos Anjos de Borba, do Setor de Educação da Universidade Federal do Paraná. 
cursos de diferentes atores, em especial pela perspectiva das jovens negras que estudavam nessa turma. Em abril de 2019, houve possibilidade de retornar a campo e firmar o diálogo com as principais interlocutoras do trabalho, que concederam entrevistas em outubro do mesmo ano.

A pergunta que orientou a pesquisa era: de que maneira estudantes negras em formação docente articulam suas identidades, tendo em vista suas trajetórias escolares e a intersecção entre raça e gênero? Em outras palavras, o objetivo do trabalho era compreender a maneira como mulheres negras definiam suas identidades no âmbito da formação docente, ou seja, tanto enquanto estudantes quanto como futuras professoras, e o modo como a escola atuava nesse sentido. De modo especial, buscava-se entender quais aspectos essas jovens negras enunciavam como relevantes em sua formação identitária.

Pesquisar as identidades negras em formação no contexto escolar dialoga com diversos(as) autores(as) que se dedicaram a compreender os modos como instituições de ensino socializam estudantes negros(as), bem como os conteúdos trabalhados e a forma de lidar, tanto cotidianamente quanto teoricamente e pedagogicamente com a negritude. Certos(as) autores(as) tensionam a educação escolar no sentido de refletir acerca de suas práticas de conformação de corpos estudantis, ideias, bem como de ideologias raciais e conhecimentos/saberes possíveis e, sobretudo, aceitos nesse contexto escolar e na sociedade, de maneira mais ampla (Louro, 1997; Duschatzky \& Skliar, 2000; Rosemberg, 2014; Gomes, 2007; Cavalleiro, 2006). Para eles(as), a educação escolar, através de currículos e práticas, seria um forte incremento na formação das identidades dos estudantes. O que se questiona é a maneira como interferiria na construção das identidades das mulheres negras que lá se formam.

Para além de refletir sobre o papel da escola, há os conflitos e as agências vivenciados e articulados pelos próprios indivíduos ao longo de suas vidas, fazendo com que (re)pensem as suas identidades em termos dos diferentes marcadores sociais que os atravessam (Hall, 2006; Woodward, 2014). Nesse sentido, as identidades não são fixas, mas fluidas e sobrepostas, interseccionadas pela raça e pelo gênero (Crenshaw, 2004) e se colocam de acordo tanto com os padrões de desigualdade definidos socialmente quanto em relação ao encontro com a alteridade. São as estratégias de autoafirmação e legitimação frente a esse encontro que aqui se discutem.

Buscando entender os encontros e desencontros no jogo das identidades de mulheres negras no âmbito da educação formal, o caminho encontrado foi a realização da etnografia. A etnografia permite, além de perceber a visão dos diferentes agentes, observar as tensões que se colocam quando se afirma uma identidade, sobretudo uma identidade rechaçada socialmente quando reivindicada politicamente (Munanga, 2012). A etnografia permite, ainda, uma percepção acerca da presença em campo enquanto pesquisadora negra na escola, investigando a maneira como "raça" e os possíveis racismos apareciam nesse ambiente. A identidade racial e os discursos acerca de sua formação foram não só o objeto de investigação, mas também fontes da tensão, adicionada ao longo de todo o trabalho de campo, como veremos adiante. 


\section{Identidade, diferença e escola}

Ao se tratar dos estudos de identidades, colocam-se enquanto primeiras perguntas: o que são as identidades? Como se formam? Hall (2006) aponta que há diferentes posições de sujeito ocupadas por um mesmo indivíduo e que as identidades são construídas no âmbito das diversidades, como formulações históricas e sociais sobre a diferença. Para Woodward (2014), a marcação da diferença, por sua vez, ocorre tanto por meio dos sistemas simbólicos de representação quanto por formas de exclusão social. A pesquisadora aponta que tal processo passa por uma interpelação quanto a uma posição de sujeito. Esse procedimento nomeia e, ao mesmo tempo, posiciona o sujeito que é, assim, reconhecido e produzido por meio de práticas e processos simbólicos.

Nesse sentido, Gomes (2002) propõe que a identidade se constrói na relação com o "outro", é negociada, intermediada pelo reconhecimento do "outro". A pesquisadora aponta, ainda, que é nos âmbitos da cultura e da história que se definem as identidades sociais, dentre estas, aquelas de raça/cor e gênero. "Reconhecer-se numa delas supõe, portanto, responder afirmativamente a uma interpelação e estabelecer um sentido de pertencimento a um grupo social de referência." (Gomes, 2003:171).

Para Munanga (2003), raça é tanto uma categoria que designa um pertencimento étnico como uma categoria político-ideológica. Tomando a negritude enquanto forma de identificação, o autor aponta que sua construção remonta à questão da mestiçagem, que, segundo o antropólogo, figura como uma barreira à identidade negra no Brasil, através da ideologia do branqueamento. Aliado a tal ideal, a discriminação racial no país seria velada, não havendo segregação legítima perante a lei, mas um sistemático afastamento da população negra das esferas do poder e o rechaçamento de sua cultura. Construir-se enquanto negra e negro, segundo o autor, supõe as barreiras impostas por uma sociedade marcada pela desigualdade racial e pela discriminação. Segato (2005), por sua vez, aponta que raça é signo: ao se deparar com a dificuldade de definir quem é negra e negro no Brasil, expõe que raça não trata de uma qualidade inerente à natureza do sujeito racializado, mas diz respeito a uma forma de qualificação ancorada nos sistemas de representações sociais. E estes, no Brasil, são essencialmente discriminatórios contra as negras e os negros.

Nogueira (2007) aponta que o racismo brasileiro se constitui a partir de critérios fenotípicos. Esse "preconceito de marca" difere do preconceito de origem por levar em consideração a "aparência racial". Ao mesmo tempo em que é elemento mobilizado para a discriminação, o movimento da negritude enquanto militância propõe apropriar-se desse corpo e ressignificá-lo enquanto um corpo político, que valorize esses traços fenotípicos, atribuídos a uma ancestralidade africana. Portanto, o corpo e o cabelo, tal como ressalta Gomes (2008), são elementos essenciais da identidade negra.

O objetivo da pesquisa aqui apresentada consistiu, pois, em compreender como mulheres negras articulam suas identidades em um espaço formal de educação, tendo em mente a complexidade do processo de formação identitária das negras e dos negros no Brasil, bem como a intersecção entre raça e gênero, que marca suas diferentes posições de sujeitos no mundo social. Para compreender tal complexidade, bem como a manifestação dessas identidades - e, além disso, tendo em vista a tentativa 
de aproximação com uma forma de fazer ciência que repense a racialização das estruturas de poder e saber -, optamos pela etnografia.

Puentes (2015) tensiona a noção de campo etnográfico através da perspectiva da epistemologia decolonial, que é, por excelência, um fazer rebelde, que questiona a academia e seus estatutos de verdade: como ser metodologicamente decolonial quando se é epistemicamente desobediente? Sua proposta não aponta um manual de boas práticas, mas princípios que devem orientar o trabalho de campo e a escrita etnográfica: abandonar a ideia de narração como um artifício literário para igualar pesquisador(a) e pesquisados(as); pensar a pesquisa a partir do compromisso com os(as) pesquisados(as); partir de uma reflexão sobre quais seriam os grupos que não se importariam com a estimativa realista da sociedade e concordariam com a "objetividade" da ciência; por fim, ter em vista quem se beneficia com as desigualdades de posições na sociedade.

Além disso, coloca-se a discussão sobre os princípios que orientam o trabalho etnográfico. Peirano (2014) propõe que etnografia não é meramente uma ferramenta metodológica, mas que toda etnografia contém em si o potencial de transformação teórica do campo de conhecimento. Neste artigo, nossa perspectiva é de que as etnografias promovam também uma transformação epistemológica e gerem uma reflexão sobre as bases do conhecimento, os papéis instituídos (inclusive em campo), assim como acerca das disputas e tensões envolvidas.

Ao pensar a etnografia na escola, André (1995) defende o uso da pesquisa de campo na investigação sistemática da prática cotidiana nesse universo. Aponta que, a partir dos anos 1970, a pesquisa qualitativa passou a ser utilizada na educação como meio de compreender o dia a dia escolar, configurando os estudos de análise de interação entre professores(as) e estudantes. Essa abordagem, guiada pela psicologia comportamentalista, se mostrou limitada ao transformar as interações em dados comparáveis e mensuráveis, ao invés de abarcar as complexidades das relações sociais estabelecidas no interior do ambiente escolar.

A alternativa encontrada pelos(as) pesquisadores(as) foi a abordagem antropológica, reconhecendo a multiplicidade de sentidos que circundam esse espaço e o universo cultural no qual a escola está inserida. São assim adotados registros de campo, gravações, análises de documentos, entrevistas e fotografias, buscando remontar os cenários em suas singularidades. Com isso, André (1995) assinala a possibilidade de documentar aquilo que é extraoficial, de revelar os encontros e desencontros, as ações dos diferentes atores, a linguagem, as formas de comunicação e os significados (re)criados nesse ambiente, permitindo compreender mecanismos de dominação e resistência articulados na escola.

Ainda segundo André, autores da área de Educação reconheceram, no final da década de 1970, a relevância da produção a partir do paradigma socioantropológico na escola, apontando a necessidade dos valores e das posições de pesquisadores(as) serem revelados em seus trabalhos. Assim, as pesquisas qualitativas, em especial a abordagem etnográfica, ganharam popularidade na área da educação no Brasil, a contar de 1980. Nos últimos anos, diversas etnografias em escolas brasileiras foram produzidas. Destacamos, neste sentido, o trabalho de Pereira (2010), sobre a experiência de jovens em contextos periféricos em São Paulo, a partir de uma etnografia que contempla a escola, reconhecendo a centralidade da ludicidade nas relações estabelecidas entre eles e com docentes, bem como revelando a joco- 
sidade como uma estratégia de microrresistência à atribuição de estereótipos e preconceitos por parte de professores(as).

Lima (2018) e Cipiniuk (2013) realizaram etnografias no contexto da Educação de Jovens e Adultos, acerca da retomada da escolarização e sobre os processos de aprendizagem. Silva $(2017,2020)$, por sua vez, se dedicou a analisar a prática educacional enquanto resistência no caso da educação escolar quilombola. Em sua pesquisa inicial, a autora centrou sua etnografia em uma escola localizada em território de quilombo e, adiante, em dissertação de mestrado, investigou comparativamente tanto a educação escolar quilombola quanto a educação escolar para quilombolas.

São múltiplos, portanto, os estudos que têm aberto o diálogo entre a educação e a antropologia, seja através da perspectiva dos processos educativos, das sociabilidades e resistências na educação, seja pensando a partir dos referencias antropológicos de forma mais restrita. Essa pesquisa se configura pela análise do que André (1995) chama de “dimensão pedagógica”, vislumbrando a interação entre professor(a)-estudante-conhecimento; “dimensão organizacional”, que aparece na definição das posições de poder, inclusive no que se refere às possibilidades e aos limites da realização da pesquisa de campo; e “dimensão sociopolítica/cultural”, pensando os processos de ensino-aprendizagem em relações raciais, nas interações professores-estudantes e, sobretudo, considerando os valores sociais que circundam a prática educativa.

Ao analisar o caráter social e cultural da educação, Duschatzky \& Skliar (2000) apontam que a escola está envolta pelo paradigma da modernidade, que se desenvolveu através do controle da alteridade e da construção de fronteiras fixas entre "nós" e "outros". Tal construção binária institui diferenças culturais baseadas em traços essencializados. Desse modo, constrói-se o "outro" como fonte de perigo: o "outro" é perigoso porque representa tudo o que é indesejável para o "nós". A crença no "outro" como origem de todo mal teria sido o mito constitucional da educação, cujo propósito era eliminar e corrigir as "falhas", ou seja, as diversidades. Gomes (2007), Arroyo (2015) e Walsh (2009), entre outros, apontam a origem do pensamento educacional ocidental inscrita na lógica da dominação colonialista, ou seja, no processo de desvalorização dos conhecimentos, das práticas e vivências daqueles considerados “diversos". Identidades estas que, segundo Gomes (2007), tal como a diversidade, se constroem enquanto processos, em determinado contexto histórico, social, político e cultural.

Quando se reflete sobre o currículo oculto, não somente pelos documentos de educação, mas pelas práticas e narrativas estruturadas a partir deles, com que olhar foram e são vistos os(as) estudantes nas suas diversas identidades? Diante de uma perspectiva educacional que mais exclui e torna exótica a diferença do que a integra de fato, tem-se um debate sobre diversidade na sociedade e no contexto escolar que surgiu das correntes de crítica à modernidade, com novos movimentos sociais reivindicadores de políticas de reconhecimento de especificidades identitárias e culturais, bem como críticos do monoculturalismo da globalização (Candau, 2000 apud Rosemberg 2014:746).

A partir da década de 1970, passou-se do discurso da igualdade para o discurso da diferença, através de movimentos étnico-raciais e do feminismo. Nesse contexto, tais insurgências passam a demandar um currículo que contemple as diversidades (Arroyo, 2015; Gomes, 2007). Nesse diálogo, Walsh (2009) expõe a relação entre interculturalidade crítica e pedagogia decolonial. Recorda, para 
tanto, que a colonialidade estabeleceu uma hierarquia social racializada, segundo a qual as categorias binárias justificam a inferioridade e desumanização dos povos colonizados - determinando a colonialidade do ser -, e o eurocentrismo é pressuposto como hegemônico, gerando a colonialidade do saber.

A aceitação da diversidade na educação enquanto prática limitada foi discutida por Rosemberg (2014). Para a autora, não basta, por exemplo, trabalhar relações interpessoais antirracistas entre estudantes; mostram-se necessárias políticas que destinem verbas para o acesso da população mais marginalizada à educação escolar de qualidade. Ela propõe uma reflexão sobre as desigualdades educacionais no Brasil, levando em conta as dimensões estrutural e simbólica na construção das desigualdades educacionais. Em estudo publicado em 1987, por exemplo, a autora analisa as relações raciais e o rendimento escolar através dos dados da Pesquisa Nacional por Amostra de Domicílios (Pnad) de 1982 e do Censo de 1980 do Instituto Brasileiro de Geografia e Estatística (IBGE). Naquele contexto, estudantes negros(as) apresentavam índices de exclusão e repetência maiores que o dos(as) brancos(as), sendo as crianças negras excluídas mais cedo dos sistemas de ensino e tendo trajetórias escolares mais acidentadas, com maiores reprovações e períodos de abandono da escola.

Tais dados foram retomados por Pinto (1993) que assumiu, já na década de 1990, a existência de um ambiente escolar hostil e indiferente aos problemas enfrentados pelas crianças negras, sendo tal atmosfera detectada via currículos, materiais didáticos e na relação professor(a)-estudante. Cita a pesquisa de Oliveira (1992 apud Pinto 1993), na qual, em uma dinâmica sobre relações raciais na escola, um grupo de docentes teria chegado a respostas para o já constatado racismo diante das crianças negras. Suas falas vão no sentido direto da culpabilização: "a criança negra é tímida", "não sabe enfrentar a discriminação racial", "a criança negra se autodiscrimina", "a criança negra se retrai".

Valverde \& Stocco (2009), por sua vez, atualizaram os dados dos anos 1980 e 1990, apontando a lenta diminuição na diferença entre os anos de estudos de negros(as) e brancos(as). Na década de 1990 e até 2001, essa defasagem girava em torno de dois anos, chegando em 1,7 anos em 2007. Nota-se, porém, que as políticas de ampliação do acesso ao Ensino Fundamental não erradicaram o descompasso referente a anos de escolarização, e em nenhum dos indicadores educacionais a escolarização de negros(as) ultrapassou a de brancos(as). Diante dessas políticas, a distorção idade-série foi reduzida para a metade entre 1993 e 2007; porém, estudantes negros(as) continuavam tendo duas vezes mais chances de estarem dois anos ou mais atrasados em relação à sua série.

As pesquisas apontaram a diferença educacional entre brancos(as) e negros(as) tanto em relação a anos de escolarização e oportunidades quanto no sentido das relações entre escola e negritude. A resposta das escolas, entretanto, tem sido manter uma "cultura de negação" da existência de práticas racistas que corroboram tais dados. Ao contrário, há uma tendência de atribuir o fracasso escolar “à desestruturação familiar, à condição socioeconômica ou à necessidade precoce de [pessoas negras] se inserirem no mercado de trabalho, sem considerar o peso que o pertencimento racial tem sobre suas trajetórias." (Valverde \& Stocco, 2009: 914).

A presente etnografia, bem como outros estudos dessa natureza que focalizaram o tema raça/ cor na educação, pretendem abrir caminhos para a compreensão dos processos de diferenciação entre 
estudantes segundo a identidade racial e como tal distinção é acionada como desigualdade de fato no cotidiano da escola.

\section{O espaço escolar}

A pesquisa se relaciona amplamente com a vivência da primeira autora em relação à formação identitária. Desse modo, o texto utiliza adiante a primeira pessoa do singular. Além de aspectos subjetivos, a opção por empregar a primeira pessoa diz respeito a uma forma de fazer campo que não se paute em uma ideia de autoridade etnográfica, por meio de uma narração impessoal na qual a pesquisadora não aparece, como aponta James Clifford (2002).

O que pretendemos discutir é a forma como, pelo fato de ser pesquisadora e mulher negra, a presença da autora provoca recepções e percepções distintas dos diferentes sujeitos em campo acerca dessa identidade. A escolha do tema de pesquisa deriva da vivência dessa autora em diálogo primeiro com a escola e, depois, com a academia e com os movimentos negros. Estudar as relações raciais no Brasil, em especial a vivência de mulheres negras na educação, é, assim, um instrumento de autoafirmação.

Tendo em vista a identidade da própria pesquisadora, na primeira etapa do estudo, de definição do tema e problema, buscamos a estratégia metodológica que melhor atenderia a nossas demandas, no sentido de compreender esse processo de construção de identidades. Como o objetivo era trabalhar com mulheres negras estudantes em formação docente, somente a realização de entrevistas, ou uma abordagem voltada ao estudo de trajetórias mais detidamente, não seriam suficientes para entender como e se os racismos, bem como os discursos sobre diversidade de raça/cor e negritude, se manifestavam naquele cotidiano escolar.

Diante disso, como exposto, optou-se por realizar pesquisa de campo etnográfica, ou seja, uma investigação que permitisse discutir de forma reflexiva o papel enquanto pesquisadora negra no campo e que previsse o acompanhamento dos encontros e das aulas; a percepção dos tempos e espaços; a conversa com diferentes agentes que compõem a escola; além do diálogo com as interlocutoras da pesquisa, realizados na forma de entrevistas semiestruturadas e registrados em caderno de campo. A realização desse gênero de estudo prevê um compromisso com as pessoas com as quais dialogamos, principalmente com as interlocutoras que, dada minha trajetória e o debate com a literatura sobre o tema, era sabido de antemão que detinham identidades subalternizadas, portanto, potencialmente excluídas e alvos de preconceitos na escola.

Em outro sentido, fazer campo, isto é, estar em uma escola enquanto mulher negra na posição de pesquisadora, advinda de uma universidade federal, poderia colocar uma tensão interessante frente ao corpo docente e às estudantes: como a escola veria uma pesquisadora jovem, negra, de classe trabalhadora? Como as estudantes negras veriam uma mulher negra, jovem, de classe trabalhadora, também estudante, na posição de quem investiga e questiona a realidade?

Ir a campo considerava que minha presença poderia modificar, em certa medida, os cenários a serem observados, reconhecendo de antemão que já se colocaria uma diferença em relação às interlocutoras, por conta da posição de quem investiga. Pesquisar em campo envolve relação de aproximação, 
mas também relação de poder. Foi com tudo isso em mente que se decidiu pela etnografia. As questóes aqui discutidas apareceram de diferentes formas e através de diferentes atores ao longo de toda a presença no campo, conforme apresentado adiante.

O contexto do estudo, reafirma-se, é a trama de discriminações, disputas e atribuição de desigualdades no interior do campo educacional, através das identidades negras. Ou seja, não se toma a "cultura nativa" como uma totalidade a ser esquadrinhada e explicada; o que se pretendeu foi observar como, de fato, se acionam os símbolos e as representações, verificar as posições em campo e, prioritariamente, problematizar a forma como as coisas estão constituídas no ambiente escolar no que se refere às mulheres negras e à negritude em geral.

Houve a escolha por trabalhar em escola pública, cuja rede é a mais abrangente no país: segundo dados do Censo da Educação Básica de 2018 (Inep, 2019), 81\% das matrículas na Educação Básica (desde a Educação Infantil até o Ensino Médio) estão em instituições estatais de ensino. A escola pública abriga estudantes oriundos de famílias com menor renda e, tal qual aponta Rosemberg (1987), existe forte relação disso com o fato de ser pobre, assim como ser negra e negro, no Brasil. Tal tendência é corroborada pelos dados do último censo do IBGE (2011), que apontou que 50\% da população negra (pretos e pardos) tinha rendimento nominal mensal entre $1 / 4$ e dois salários mínimos, menor que qualquer outro grupo de raça/cor no país.

Optou-se, portanto, por trabalhar com a escola pública pensando nessa correlação entre maior número de matrículas de estudantes negros e menor renda em geral dos estudantes, da qual poderia advir a necessidade de conjugar trabalho e estudo. Entender se essas jovens negras precisavam trabalhar e estudar, qual tipo de trabalho realizavam, onde se empregavam, qual a sua participação na composição da renda familiar, etc., também era uma possibilidade interessante oriunda desse contexto. O curso de formação de docentes que se pretendia investigar, portanto, era ofertado em escola pública e integrado ao Ensino Médio.

O primeiro passo da pesquisa foi circunscrever o locus no qual se realizaria o campo: escolas públicas de Curitiba (PR) que oferecessem formação de docentes. A análise limitou-se à cidade de Curitiba por saber, de antemão, da existência de escolas que oferecem a formação de docentes há décadas, sendo referências na área. Além disso, havia relação das autoras com o movimento negro na cidade, estratégia que possibilitaria mapear as redes nas quais as estudantes negras poderiam estar envolvidas. À época, duas escolas ofertavam cursos de formação docente na cidade. Enviamos solicitação para realizar a pesquisa em ambas e tivemos o aval da direção para realizar o estudo em uma delas, localizada na região central curitibana e cujos estudantes estão espalhados por diversos bairros e mesmo na região metropolitana.

Tal instituição é uma das mais antigas do Paraná e, sendo uma escola centenária, conta sua história através da arquitetura e do hall de antigos diretores, que se localiza pouco adiante da sala da direção, logo na entrada. Todos os dias, estudantes, professores(as) e funcionários(as) passam por mais de 50 quadros dos ex-dirigentes e docentes notáveis, desde o final do século XIX, antes mesmo da abolição da escravatura no Brasil. Dentre os rostos expostos, há somente um professor negro. Há cinco mulheres, 
nenhuma negra; de resto, todos são homens brancos. A história que a escola narra, em suas paredes, é a de uma instituição de excelência constituída majoritariamente por homens brancos.

As salas de aula, divididas em três andares, circundam a quadra que fica no térreo e serve como corte, pátio visível dos corredores que concentra os estudantes durante os intervalos, momentos de interação. Da quadra, é possível ver todas as salas, e de todas as salas se vê a quadra e os demais recintos de aula. A estrutura remete ao panóptico de Foucault (1987) e à forma como tal espaço serviu para a vigilância das estudantes que seriam professoras, reproduzindo uma noção de ordem e controle. Há um anexo de construção mais recente, cuja estrutura é totalmente distinta: a quadra é separada das salas, os corredores são mais estreitos e, de uma sala, se vê somente o corredor. Esse anexo teria sido projetado, segundo relatos, quando a escola passou a receber meninos.

\section{Identidades negociadas}

As distinções e a história da escola aparecem não só no prédio, mas também nos discursos. Na primeira visita, na qual houve contato com os(as) pedagogo(as) e com a direção, percebi que, ao falar do tema e da metodologia, imediatamente o pedagogo que recebeu a proposta se interessou, chamando outra pedagoga para ouvir sobre a pesquisa. Ele contou que havia uma turma no período noturno com várias estudantes negras, em suas palavras, "meninas engajadas", "mais militantes”, mas que "às vezes exageram", em especial no conflito entre elas e o único menino da sala. Segundo o profissional, "um menino alto, forte, que botava medo, mas que não fazia mal a ninguém”.

Esse pedagogo disse ainda ser interessante que a etnografia focasse nessa turma do terceiro ano do período noturno para, além de contemplar a pesquisa, ajudar a resolver esse conflito. Diante do projeto de pesquisa, bem como das recomendações e dos termos de sigilo, a diretora autorizou o estudo, exigindo tal contrapartida. Como se pôde observar depois, a disputa entre estudantes se dissolveu, ficando a relação entre ambos os polos marcada por uma denúncia de discurso contra a negritude no cotidiano escolar.

Percebi também uma insistência do pedagogo e da diretora em perguntar se a pesquisa não abrangia a realização de estágio, ainda que estivesse com o projeto e a carta de recomendação em mãos. Perante a insistência dos(as) pedagogos(as) em questionar o que, afinal, se estava fazendo ali, apesar de admitirem a presença, foi possível notar uma postura de dúvida em relação à pesquisadora. Como notei adiante, essa dúvida se transformou em discursos de resguardo por parte da coordenação pedagógica, já que, conforme emergiram em algumas falas, olhares e questionamentos posteriores, havia um incômodo em relação ao tema. Apesar da abertura inicial à pesquisa, depois o corpo pedagógico passou, de certa forma, a temer o que estava sendo visto, como estava sendo visto e o que seria dito.

O primeiro contato com a turma do período noturno, acompanhada entre outubro e novembro de 2018 e de abril a junho de 2019 , se deu por meio de uma terceira pedagoga, que me apresentou dizendo que acompanharia as aulas e que estava fazendo uma pesquisa sobre as estudantes negras na escola. Nesse momento, algumas delas comemoraram. 
A sala em que estavam era composta por grandes mesas compartilhadas. Uma jovem, Dandara ${ }^{2}$, convidou-me para sentar ao seu lado e se apresentou. Durante a aula, estavam acontecendo apresentações de trabalhos sobre o tema "preconceito". Algumas estudantes, dentre elas Tereza e Carolina, além de duas colegas que eu identifico como brancas, expunham seu trabalho cujo título era "O preconceito mata”, ofertando dados sobre genocídio da população negra, o negro no mercado de trabalho e violência policial.

Tereza e Carolina contaram casos de racismo dos quais tomaram conhecimento e outros dos quais elas mesmas foram vítimas. Enquanto isso, parte da turma conversava, outra parte mexia no celular, outra prestava atenção. Ficou evidente que Tereza e uma das suas colegas brancas se colocavam como militantes políticas. Tereza usava cabelo Black Power, brincos que representam pentes-garfo ${ }^{3} \mathrm{e}$ camisetas com frases como "lute como educa". Assim que ela começou a se manifestar, revelou-se perceptível, ainda, o desdém por parte de outras meninas da turma, que pareciam não dar crédito ao que ela falava e, dessa forma, quando ela falava, não era ouvida.

Dentre os relatos de racismo dos quais tomaram conhecimento, Carolina contou o caso da invasão de um baile pela polícia e a agressão de seus organizadores. Esse baile é referência na cidade de Curitiba como reunião da população negra da cidade, sendo conhecido por tocar ritmos como black, soul, passinho e samba, além de promover encontros, danças e estéticas típicas negras, reunindo a militância da cidade, tanto a ligada às universidades federais quanto aquela dos mais velhos, membros de organizações e associações mais antigas. Carolina conhecia militantes negros(as) e tinha contato com eles. Tereza, por outro lado, citou casos que vão além do âmbito local, como o assassinato da vereadora pelo Rio de Janeiro (RJ) Marielle Franco, em 2018. Tereza, conforme fiquei sabendo mais tarde, era militante ligada a um partido político.

Descobri então que Carolina e Tereza eram primas. Mas os grupos de amizade e as posições políticas de ambas se mostravam distintas: Tereza criticava o então candidato à Presidência da República, Jair Bolsonaro, enquanto Carolina falava da atuação da polícia local. Além dessa divergência de posicionamento e de ligação com a militância, Carolina e Tereza se diferenciam por outro aspecto essencial para compreender esse jogo de identidades: nas palavras de Tereza, Carolina é negra de pele retinta, enquanto Tereza é negra de pele mais clara. A percepção de Tereza sobre tal questão apareceu no momento da entrevista, quando comentou que o fato de ter a pele mais clara influenciava diretamente na percepção dos demais sobre sua identidade. Carolina se colocava muito menos que Tereza, no sentido de verbalizar uma contestação ou um descontentamento em relação a discursos e opressões do cotidiano escolar. Mas, quando Carolina falava, as pessoas a ouviam.

Depois da apresentação delas, outro grupo, composto por Esperança e uma colega branca, iniciou a exposição de seu trabalho sobre intolerância religiosa. Imediatamente, houve uma heteroidenti-

\footnotetext{
2 No decorrer do texto, ao nos referirmos às estudantes com quem houve contato em campo, atribuímos nomes fictícios referentes a personalidades da cultura afro-brasileira. A primeira é Dandara de Palmares (S.I. -1654). Depois, Tereza de Benguela (S.I. - viveu no século XVIII) e Carolina Maria de Jesus (1914-1976). Após, Esperança Garcia (1751-?) e João Francisco dos Santos, conhecido como Madame Satã (1900-1976). A seguir, Maria Firmina dos Reis (1822-1917) e Antonieta de Barros (1901-1952). Por fim, Luiza Mahín (S.I. - viveu no século XIX) e Laudelina Campos de Melo (1904-1991).
}

3 Pentes-garfo são pentes utilizados para ajudar a dar volume ao cabelo crespo, formando assim o emblemático penteado Black Power. 
ficação de Esperança como negra. Ela tinha a pele retinta, porém, seu cabelo era liso. Esperança possuía traços que são atribuídos como características do fenótipo negro. $\mathrm{O}$ tom da apresentação das duas, porém, era muito mais ameno que o da exposição anterior: as meninas falavam sobre o preconceito contra evangélicos, a forma como a religião cristã as ajudou, os comentários maldosos sobre sua crença e ainda acerca das doutrinas das diferentes igrejas evangélicas. Em momento algum, essas estudantes abordaram o racismo religioso, por exemplo, ou as religiões de matriz africana (ou afrobrasileiras). Quem levantou a questão do preconceito religioso contra a Umbanda foi Carolina, que pediu a palavra para contar casos de terreiros invadidos e destruídos.

Entre uma apresentação e outra, Dandara perguntou-me onde estudava e se havia ingressado por cotas para pessoas negras, conforme Lei $n^{\circ}$. 12.711/2012. Quando contei ter acessado a universidade por cotas para estudantes de escola pública, Dandara me disse que deveria ter tentado por cotas raciais. Ao longo do trabalho de campo, minha identificação, por parte de Tereza e Dandara, enquanto negra, possibilitou abrir diálogo e uma aproximação maior dessas interlocutoras. Essas meninas - com as quais posteriormente realizei entrevistas - acabaram contando coisas em tom de confidencialidade, dando a entender que tais relatos e diálogos eram frutos de uma experiência compartilhada por mulheres negras.

Ao mesmo tempo em que houve essa identificação, ficando subentendida uma ideia de compartilhamento de opressões, buscou-se, porém, tomar o cuidado para não homogeneizar as vivências das mulheres negras. Os primeiros minutos na turma, vendo a apresentação do trabalho "O preconceito mata”, já mostraram que ser uma mulher negra não é uma coisa única no cenário em que eu estava estudando. A vivência delas é múltipla e interseccionada pelas outras posições de sujeito ocupadas por essas meninas, tais como de esposa, como no caso de Esperança; de professora, no caso de Carolina; de militante política, como Tereza; de trabalhadora, como Dandara. Portanto, a primeira armadilha desse jogo de identidades que me apareceu em campo foi uma possível tendência à generalização, contornada por meio do diálogo mais aberto com as demais estudantes da turma.

Outro tensionamento se deu no sentido inverso: enquanto investigava as noções de militância e engajamento, bem como os discursos defendidos pelas meninas negras, Dandara colocou-me à prova justamente nesse sentido. Ela contou participar de um projeto que oferecia cursinho pré-vestibular exclusivamente para jovens negros, apontando que tal iniciativa mobilizava, em suas reuniões, toda a rede de militantes no contexto da cidade de Curitiba. Por conta do público-alvo escolhido, Dandara disse que o projeto poderia ser visto como racista sob o olhar da branquitude. Após expor isso, Dandara perguntou se eu frequentava o movimento. Ficou implícito que se referia ao movimento negro. Minha resposta foi negativa, ao que ela respondeu: "É complicado... algumas coisas são complicadas. Eu, por exemplo, não concordo com tudo”. Após, Dandara falou que seria interessante visitar uma dessas reuniões, sugestão na qual percebi uma cobrança por posicionamento.

Quando a turma se encontrava para aulas em sua sala habitual, mostrava-se perceptível que os grupos de afinidades tinham uma divisão por raça/cor e, consequentemente, do espaço. As jovens negras militantes e João sentavam-se de um lado; as demais meninas, negras e brancas, do lado oposto. Havia um corredor vazio entre ambos. Optou-se por acompanhar as aulas, num primeiro momento, 
na carteira próxima à do(a) professor(a), à frente da sala, local no qual se poderia ver a turma toda e perceber quem interagia com quem, quais eram os grupos de amizades. Logo atrás de mim, acomodavam-se Dandara, João e Esperança. Atrás de João, ficava Carolina, próxima à sua prima Tereza. Todo esse grupo interagia entre si durante as aulas, intervalos, entrada e saída da escola.

A briga que o pedagogo havia comentado se estruturava em torno de João e Tereza, que constantemente tinham pequenas discussões, por conta do suposto apoio do garoto ao então presidenciável Jair Bolsonaro, a quem a jovem atribuía discursos e políticas racistas e homofóbicos. Do outro lado da sala, como dito, havia outro grupo de meninas negras que interagia prioritariamente com as meninas brancas, que se sentavam nas carteiras ao seu redor. Mas essas amizades pareciam ser colocadas à prova em determinados momentos, quando o assunto era raça/cor.

Numa aula de filosofia, o professor abordava o tema do "politicamente correto". Uma jovem branca, de classe média, sempre vestindo roupas de marca e portando um celular caro, perguntou, então, qual a diferença entre falar "preto" e "negro". Essa menina era amiga de Maria Firmina e Antonieta. Começou, a partir disso, uma discussão em sala sobre como se devia falar, se "preto" ou "negro". A garota branca disse: "Se eu sou negra e chamo de preta ou preto, não é preconceito, não tem problema, mas se eu falo [enquanto branca], tem problema”. Maria Firmina replica que a denominação correta é negra: "Eu sou negra, mas tenho a pele mais clara". A colega então responde: "Não, você não é negra, é parda igual a mim”. Carolina e Tereza reagem: “Não existe pardo, pardo é papel!”.

Enquanto acontecia essa discussão, Dandara perguntou ao professor qual embasamento ele estava usando para afirmar sua posição nesse debate, uma vez que o docente afirmou que "preto é cor" e o correto a pessoas seria chamar de "negro". Maria Firmina, que se identifica como uma mulher negra, defendeu tal posição. Mas, ainda sim, recebeu questionamento de suas próprias amigas brancas quanto à sua identidade e, quando a reafirmou, foi rechaçada.

Maria Firmina interagia, prioritariamente, com o grupo de meninas brancas. Ela tinha longos cabelos cacheados, que utilizava sempre com bastante produto fixador para tirar todo o volume e ficar todo alinhado. A esse grupo de amigas, que, ao mesmo tempo, é composto por meninas brancas de classe média e por meninas negras sem uma postura militante, pertencem Antonieta e Luiza. Antonieta usava um visual parecido com o de Maria Firmina. Depois de algumas visitas minhas a campo, notei que ela passou a alisar os cabelos com mais frequência. Já Luiza performava uma condição financeira superior a todas as outras estudantes, com exceção de sua melhor amiga, branca, que sempre se sentava ao seu lado. Luíza tinha cabelo liso e pele negra mais clara.

Nesses grupos de afinidades e de tentativas de legitimação, mostravam-se relevantes alguns fatores na definição das identidades raciais dessas jovens: a cor da pele importava, assim como a textura dos cabelos - a aparência racial, conforme aponta Nogueira (2007); a condição social era também decisiva, estruturando amizades entre aquelas de circunstâncias materiais de vida semelhantes; havia ainda um custo, em termos de amizades possíveis, quando se reivindicava a militância política em torno de "ser mulher negra”. Algumas estudantes pareciam optar por estratégias de microrresistência nesse sentido, reivindicando a identidade em determinados momentos ou, então, ignorando tal elemento enquanto 
formador de sua subjetividade. Já outras pareciam assumir o risco e contestavam, constantemente, discursos e práticas que entendiam como impasses à luta antirracista.

Outro eixo importante da pesquisa foi a "identidade de pesquisadora" constantemente posta à prova em campo por docentes e pedagogo(as). A professora de inglês, por exemplo, diante do tema da pesquisa e do acompanhamento das aulas, demonstrou incômodo e exigiu que não houvesse interferências em suas aulas. Nota-se a desconfiança que, por vezes, parecia estar associada ao fato da pesquisadora ser jovem e se vestir como as estudantes (que não têm uniformes), isto é, uma pessoa parecida com as discentes. Essa professora várias vezes me atribuiu tarefas em sala tal qual fazia com estudantes, reclamando do atraso para entrar na sua sala mais de uma vez - lembrando que, em certas ocasiões, as alunas me confidenciavam impressões sobre as falas de colegas e docente, bem como sobre a escola, entre uma aula e outra, sendo esse momento de troca de ambientes essencial para o estreitamento das relações e construção do caderno de campo.

Outra professora, uma senhora que se apresentou como uma das docentes mais antigas da escola, que lecionava algumas disciplinas específicas da formação de docentes, mais de uma vez tratou-me como "estagiária", pedindo para vigiar a turma, levar as estudantes a outra sala, assim como para observar quem estaria fazendo as atividades propostas. Recordo que, para todos(as) os(as) docentes minha apresentação foi como pesquisadora.

Em outro momento, justamente no dia 20 de novembro, durante o intervalo das aulas, as estudantes ficaram em sala no intervalo para terminar trabalhos. Enquanto isso, no corredor, era possível observar cartazes sobre o Dia da Consciência Negra. Alguns deles diziam "Vidas Negras Importam" e traziam dados informativos sobre a segregação racial no Brasil. Enquanto tirava fotos desses cartazes, uma das pedagogas pergunta o porquê das fotos, num tom acusatório de desconfiança. Diante da ex-

plicação sobre a pesquisa, a pedagoga disse que queria colar em cima um cartaz que dissesse: "todas as vidas importam".

Afinal, quem é pesquisadora e quem é estagiária? Quais figuras ocuparam, historicamente, essa posição? Quem pode observar, anotar e pesquisar sem levantar suspeita ou desconfiança? Parecia muito mais fácil conceber a presença como estagiária, tanto por uma dificuldade de compreensão sobre o papel de uma pesquisadora, talvez, quanto por uma questão de poder: a estagiária é a auxiliar docente. Ou seja, na medida em que tratavam como estagiária, as professoras, os professores, as pedagogas e o pedagogo estabeleciam um lugar hierárquico inferior a eles(as) próprios(as).

\section{Autodeclaração e pigmentocracia}

Tendo já observado os grupos de afinidades, os discursos e posturas das estudantes ao longo de dois meses, foi possível identificar que "raça” não era tema apaziguado na turma, ao contrário, gerava polêmicas e disputas. As alunas não pareciam ter uma conformidade acerca de quem era negra, quem era branca, quem falava e quem podia falar sobre o tema.

Foi nesse cenário que houve a aplicação, nas últimas visitas em 2018 à escola, de um breve questionário de autoidentificação de raça/cor entre as estudantes, buscando entender como as jovens negras 
não militantes se definiam, uma vez que boa parte delas nunca tinha assim se declarado, nem havia se colocado em nenhum dos debates sobre raça e racismo. Como buscava compreender a construção da identidade enquanto mulheres negras das estudantes, a sua autoidentificação importava muito mais que a heteroclassificação.

Mais que atribuir uma identificação de raça/cor, por se tratar de um estudo sobre a formação de identidades, era necessário observar a forma como essas meninas se definiam, sem que precisassem falar para as demais e serem cobradas pelos seus posicionamentos. Por esse mesmo motivo, optou-se por não fazer uma aplicação individual, perguntando diretamente às estudantes, decidindo-se por questionários escritos sigilosos para as demais colegas. Como buscava entender as particularidades das diferentes possibilidades de ser negra, pelo clima de discordância e desagrado à postura militante de algumas, avaliei que outras não se sentiriam à vontade para se expor nessa questão, nem para descrever sua identidade de raça/cor em voz alta, uma vez que essa enunciação poderia envolver uma construção de narrativa mais elaborada.

O modelo das perguntas seguiu o padrão do IBGE quando aplica o censo, bem como foi o modelo replicado por Carvalho (2004) em sua pesquisa de campo numa escola de Ensino Fundamental, na qual estudava gênero, raça e relações professor(a)-aluno(a). Na primeira questão, portanto, havia as opções de resposta "branco", "preto", "pardo", "amarelo"; na segunda questão, pedia-se para que escrevessem livremente como se identificam.

Já na aplicação do questionário foi possível observar uma movimentação na turma. Algumas estudantes perguntaram se poderiam marcar mais de uma opção na primeira questão. Após, questionaram o que deveriam colocar na questão 2. Havia, portanto, tanto uma dificuldade em definir sua classificação em uma categoria discreta quanto em nomeá-la livremente. As militantes negras, porém, não tiveram essa dificuldade, sendo precisas em assinalar a opção "preta".

As pessoas que tiveram dúvidas foram aquelas que marcaram a opção "parda”, dentre elas Laudelina e Antonieta. Uma estudante inicialmente identificada como negra se declarou branca e não escreveu nada na opção descritiva, portanto, não a nomeamos neste trabalho. Além desse caso, uma aluna identificada como branca perguntou, em voz alta (o suficiente para que toda a turma ouvisse seu comentário), para uma amiga se deveria marcar a opção "parda”. De fato, ela o fez, mas sua amiga disse que a achava branca. Tereza ouviu e respondeu: “Não existe pardo, pardo é papel, e você é branca”. Imediatamente, a menina mudou a opção e assinalou "branca", não preenchendo a questão 2 .

Os resultados do questionário encontram-se no quadro a seguir, ressaltando as respostas das estudantes que se disseram "pretas" e "pardas": 
Quadro 1 - Respostas de estudantes negras(os) ao questionário de autoidentificação de raça/cor

\begin{tabular}{|c|c|c|c|}
\hline $\begin{array}{l}\text { Estudante } \\
\text { (nome } \\
\text { fictício) }\end{array}$ & Gênero & $\begin{array}{l}\text { Questão 1: Segundo } \\
\text { os critérios do IBGE, } \\
\text { como você define sua } \\
\text { raça/cor? }\end{array}$ & $\begin{array}{l}\text { Questão 2: Descreva como você de- } \\
\text { fine sua raça/cor (pode extrapolar a } \\
\text { classificação do IBGE). }\end{array}$ \\
\hline Antonieta & Feminino & Parda & "Sou mais para a cor de café." \\
\hline Carolina & Feminino & Preta & $\begin{array}{l}\text { "Minha cor, eu consigo definir em ape- } \\
\text { nas uma palavra: RESISTÊNCIA." }\end{array}$ \\
\hline Dandara & Feminino & Preta & $\begin{array}{l}\text { "Eu defino minha cor como linda, } \\
\text { porque aprendi a amá-la. Depois eu } \\
\text { a classifico como uma grande fonte } \\
\text { de representatividade. A cor negra é a } \\
\text { vitamina que alimenta o processo da } \\
\text { vida. A melanina é a proteção do corpo } \\
\text { humano!" }\end{array}$ \\
\hline Esperança & Feminino & Amarela & $\begin{array}{l}\text { "Às vezes eu me olho e me sinto "ama- } \\
\text { relada". (É uma resposta sincera)." }\end{array}$ \\
\hline Laudelina & Feminino & $\begin{array}{l}\text { (assinalou as opções } \\
\text { "parda" e "branca") }\end{array}$ & (Sem resposta) \\
\hline Luiza & Feminino & Parda & $\begin{array}{l}\text { "Cor de café com leite, mais puxada } \\
\text { para o café". }\end{array}$ \\
\hline $\begin{array}{l}\text { Maria } \\
\text { Firmina }\end{array}$ & Feminino & Preta & $\begin{array}{l}\text { "Eu amo a minha cor, minha cultura, eu } \\
\text { defino minha cor do jeito que gosto". }\end{array}$ \\
\hline Marielle & Feminino & Preta & "Me defino morena". \\
\hline Teresa & Feminino & Preta & "Preta, preta, pretinha, afrobege". \\
\hline João & $\begin{array}{l}\text { Masculi- } \\
\text { no }\end{array}$ & Preta & "Negro." \\
\hline
\end{tabular}

Fonte: Das autoras (2020).

Para além das informações apresentadas no quadro acima, Laudelina se identificou ao mesmo tempo como "branca" e "parda", ressaltando com a caneta a resposta "parda" e não escrevendo nada na segunda pergunta. Dandara circulou a opção "preta" da questão 1, com vários desenhos de coração. Luiza, que imaginávamos que se declararia branca, por conta do seu grupo de amizades e pertencimento de classe, além de nunca ter se posicionado sobre o tema, declarou-se "parda".

A identidade de Luiza provocou um autoquestionamento e a reflexividade da posição de "militante" em campo. Sua heteroidentificação seguiu o colorismo - perspectiva que divide pessoas negras entre "mais claras" e aquelas com a pele mais retinta, em geral utilizada para destituir as primeiras de posição de centralidade enquanto representantes do que se pode imaginar por "negritude", inclusive nos movimentos sociais. 
O problema do colorismo aparece também na resposta da estudante Tereza ao questionário. Tereza é uma negra de pele clara e cabelo Black Power, que constantemente é questionada sobre sua identidade de raça/cor, como contou em entrevista. Ela marcou a opção "preta" e na descrição escreveu "preta, preta, pretinha, afrobege", sendo esta última a forma pejorativa pela qual militantes que se valem do colorismo chamam as pessoas negras de pele mais clara, ou seja, os mestiços. Esperança, cuja pele é retinta e cujo grupo de amizades circunda as militantes, assinalou a opção "amarela”: "às vezes eu me olho e me sinto "amarelada”. (É uma resposta sincera)", escreveu.

Colorismo aqui é entendido enquanto modo de classificação de negras e negros através da tonalidade da pele, usando o critério pigmentocrático para estabelecer relações de validação de identidades enquanto negritude. A questão do colorismo ou pigmentocracia apareceu em diversos momentos ao longo da pesquisa de campo. Alguns dos principais estudiosos das relações raciais no Brasil, como $\mathrm{Mu}-$ nanga $(2003$, 2012) e Bento (2002), vêm discutindo contemporaneamente a relação entre identidade e tom da pele. Tais debates apontam uma maior percepção de identidade racial legítima ligada às tonalidades de pele retintas, sendo as pessoas de peles mais claras postas, por vezes, em posição de dúvida nas dinâmicas sociais em relação ao seu pertencimento étnico-racial.

Quando a estudante branca quis assinalar "parda” e foi repreendida por Tereza, outra questão aparece, aquilo que Gomes (2002) afirma: a identidade negra não se constrói sozinha, é relacional e diz respeito ao pertencimento a uma comunidade negra, ou seja, trata-se de uma identidade coletiva. Nessa perspectiva, a postura de Tereza, assim como os olhares de reprovação de Carolina e João, diante da menina branca que perguntou se deveria marcar "parda”, reivindicavam legitimidade frente à negritude enquanto pertencimento comunitário, e não como cor de pele bronzeada, como comentou Tereza após o episódio. Ser negra, para as jovens militantes, parecia estar associado a partilhar dessa identidade e das vivências de resistência frente ao racismo.

Entendemos que para as jovens mulheres que raramente demonstravam uma postura de resistência em seus discursos - ou seja, não se opunham em sala a eventuais frases racistas, não se colocavam no debate (exceto Carolina, que uma vez se posicionou) - ser mulher negra ia além desse embate discursivo. Era algo muito mais associado a ter que gerir sua vida, se virar, se manter e engendrar formas de resistências pequenas em seu cotidiano, visando a caber nos espaços institucionais dos quais necessitavam, como a escola em que estudavam e a escola em que trabalhavam.

Outro aspecto importante foram as negociações implícitas de minha presença em campo frente às estudantes que se declaravam brancas e detinham a condição de classe mais favorável. Havia uma espécie de poder simbólico que circundava as garotas brancas de classe média na sala. Buscando compreender sua aproximação com as meninas negras não militantes, alterei o local de acompanhamento das aulas para o outro lado da sala, próximo a elas, na última semana da permanência em campo.

Nessa ocasião, dia seguinte ao da aplicação dos questionários, uma menina branca questionou-me: “Já que você nos perguntou ontem, deixa eu te perguntar: como você se identifica?". Falar sobre identidades diz respeito em todo momento a disputas de posição. É como se ela estivesse dizendo que só tinha legitimidade para perguntar se tivesse uma posição clara a respeito da raça/cor. Em especial, era como se quisesse dizer que eu só poderia perguntar se me identificasse como negra de fato. Diante 
da resposta afirmando a autodeclaração enquanto negra, a estudante respondeu: "É, você até que tem os traços".

Não só nesse momento, mas em outras situações menos emblemáticas em campo, a pergunta quem é negra, quem é branca, quem fala, quem pode falar se voltou diversas vezes à pesquisadora, obrigando-me a retomar constantemente uma postura de reflexividade e, ao mesmo tempo, dando pistas sobre o que é ser uma mulher negra no contexto da escola.

\section{Considerações finais}

Neste artigo, houve a exposição de dados de uma pesquisa que aplica o fazer etnográfico no contexto escolar para investigar as manifestações das identidades de raça/cor de estudantes em formação docente. A pesquisa, guiada pelo referencial decolonial, passou primeiro pela definição do papel de pesquisadora/etnógrafa enquanto sujeito dotado também de identidade. Nesse caso, discutiram-se as formas pelas quais a identidade de mulher negra da pesquisadora oportunizou aproximaçóes no trabalho campo em relação a algumas estudantes, bem como afastamento em relação a docentes e outras estudantes.

Destacamos também a desconfiança e receio que pareciam permear a estadia em campo por parte do corpo docente após o início da pesquisa e a constante deslegitimação enquanto pesquisadora, revezes contornados pela proximidade que tal posição trouxe em relação às estudantes negras consideradas “militantes exageradas”, segundo a fala de um dos pedagogos da instituição.

A pesquisa abarcou a necessidade de legitimação da identidade racial, seja das estudantes que se reivindicavam como negras e, quando têm a pele mais clara, são rechaçadas e silenciadas, seja das estudantes que se definem "morenas", em suas palavras, e se afastam do que se identifica no discurso comum daquele contexto escolar como uma "militância exagerada". Paralelamente, quando uma estudante branca demonstra dúvida em relação à sua cor, pretendendo denominar-se parda, esta foi imediatamente corrigida pelas militantes negras, que desacreditam tal categoria enquanto identificação, entendendo que a identidade racial é política, e que "ser negra" perpassa essa percepção e uma aceitação comunitária, ou seja, uma aceitação do grupo que reivindica a negritude.

Ressaltamos, por fim, as possibilidades advindas da etnografia na pesquisa em educação e em contextos escolares. A etnografia permitiu observar e analisar discursos que corriam nos corredores da escola e proferidos por docentes no sentido de desacreditar as reivindicações das estudantes negras, ainda que, na narrativa oficial, a diversidade fosse bem aceita, tal qual a participação dessas mulheres. Por vezes, foi possível notar o descontentamento de outrem frente à fala das estudantes negras menos por suas reações verbalizadas, mas através de olhares, desvios de atenção e risadas para as colegas. Somente a etnografia permite esse nível de detalhamento e percepção de conflitos num campo que se diz harmonioso e aberto à diferença. 
Aline Adriana de Oliveira é Licenciada em Ciências Sociais pela Universidade Federal do Paraná (UFPR) e mestranda em Educação pela mesma instituição.

Carolina dos Anjos de Borba é Doutora em Desenvolvimento Rural pela Universidade Federal do Rio Grande do Sul (UFRGS) e Professora Titular da Universidade Federal do Paraná (UFPR). Atua no Programa de Pós-Graduação em Educação e atualmente coordena o Programa de Pós-Graduação em Meio Ambiente e Desenvolvimento.

\section{REFERÊNCIAS}

André, M. (1995). Etnografia da prática escolar. Campinas: Papirus Editora.

Arroyo, M. (2015). Os Movimentos Sociais e a construção de outros currículos. Educar em Revista, 55, 47-68. https://doi.org/10.1590/0104-4060.39832

Bento, M. A. S. (2002). Branqueamento e branquitude no Brasil. In: M. A. S. Bento et al. Psicologia social do racismo: estudos sobre branquitude e branqueamento no Brasil (pp. 5-58). Petrópolis: Vozes.

Cavalleiro, E. (2006). Relações raciais no cotidiano escolar: implicações para a subjetividade e a afetividade. In: A. P. Brandão (org). Saberes e fazeres: modos de ver (pp. 82-95). Rio de Janeiro: Fundação Roberto Marinho.

Cipiniuk, T. (2013). Investimentos na superação da condição social analfabeto: percursos escolarizados em temporalidade tardia (Tese de Doutorado). Universidade Federal Fluminense, Niterói.

Clifford, J. (2002). A experiência etnográfica: antropologia e literatura no século XX. $2^{\mathrm{a}}$.

ed. Rio de Janeiro: Editora UFRJ.

Crenshaw, K. (2004). A intersecionalidade na discriminação de raça e gênero. In: VV. AA. (org). Cruzamento: raça e gênero (pp. 7-16). Brasília: Unifem.

Duschatzky, S., \& Skliar, C. (2000). Os Nomes dos Outros. Reflexões sobre os Usos Escolares da Diversidade. Educação \& Realidade, 25(2), 163-177.

Gomes, N. (2002). Educação e Identidade Negra. Aletria: Revista de Estudos de Literatura, 9, 38-47. https://doi.org/10.17851/2317-2096.9 
Gomes, N. (2003). Educação, identidade negra e formação de professores/as: um olhar sobre o corpo negro e o cabelo crespo. Educação e Pesquisa, 29(1), 167-182. https://doi.org/10.1590/S151797022003000100012

Gomes, N. (2007). Indagaçôes sobre currículo: diversidade e currículo. Brasília: Ministério da Educação.

Gomes, N. (2008). O processo de rejeição/aceitação/ressignificação do corpo e do cabelo. In: N. L. Gomes. Sem perder a raiz: corpo e cabelo como simbolos da identidade negra (pp. 117-147). Belo Horizonte: Autêntica.

Hall, S. (2006). A identidade cultural na pós-modernidade. 11 ed. Rio de Janeiro: DP\&A Editora. Instituto Brasileiro de Geografia e Estatística. (2011). Censo Demográfico 2010: Características da população e dos domicílios. Rio de Janeiro: IBGE.

Instituto Nacional de Estudos e Pesquisas Educacionais Anísio Teixeira. (2019). Sinopse Estatística da Educação Básica 2018. Brasília: Inep.

Lima, A. (2018). "Onde há uma vontade, há um caminho": uma etnografia da escolarização tardia na EJA do Colégio de Aplicação/UFRGS (Dissertação de Mestrado). Universidade Federal do Rio Grande do Sul, Porto Alegre.

Louro, G. (1997). Gênero, sexualidade e educação: uma perspectiva pós-estruturalista. 2 ed. Petrópolis: Vozes.

Munanga, K. (2003). Uma abordagem conceitual das noções de raça, racismo, identidade e etnia. In: $3^{\circ}$ Seminário Nacional Relações Raciais e Educação - PENESB. Anais... Rio de Janeiro. Disponível em: www.geledes.org.br

Munanga, K. (2012). Negritude e identidade negra ou afrodescendente: um racismo ao avesso? Revista da Associação Brasileira de Pesquisadores/as Negros/as (ABPN), 4(8), 06-14.

Nogueira, O. (2007). Preconceito racial de marca e preconceito racial de origem: sugestão de um quadro de referência para a interpretação do material sobre relações raciais no Brasil. Tempo social, 19(1), 287-308. https://doi.org/10.1590/S0103-20702007000100015

Peirano, M. (2014). Etnografia não é método. Horizontes antropológicos, 42, 377-391. https://doi. org/10.1590/198053142856

Pereira, A. (2010). "A maior zoeira”: experiências juvenis na periferia de São Paulo (Tese de Doutorado). Universidade de São Paulo, São Paulo. 
Pinto, R. (1993). Movimento negro e educação do negro: a ênfase na identidade. Cadernos de Pesquisa, 86, 25-38.

Puentes, J. (2015). Descolonización metodológica e interculturalidad. Reflexiones desde la investigación etnográfica. Revista Latinoamericana de Metodología de las Ciencias Sociales, 5(2), 19p.

Rosemberg, F. (1987). Relações raciais e rendimento escolar. Cadernos de Pesquisa, 63, 19-23.

Rosemberg, F. (2014). Educação Infantil e relações raciais: a tensão entre igualdade e diversidade. Cadernos de Pesquisa, 44(153), 742-759.

Segato, R. (2005). Raça é signo. Série Antropologia, 372, 1-16.

Silva, F. (2017). Educação insubmissa: Colégio Estadual Quilombola Diogo Ramos (Monografia de Graduação). Universidade Federal do Paraná, Curitiba.

Silva, F. (2020). Escolas para quilombolas: identidade e territorialidade no Colégio Estadual Quilombola Diogo Ramos e na Escola Municipal do Campo Augusto Pires de Paula (Dissertação de Mestrado). Universidade Federal do Paraná, Curitiba.

Valverde, D., \& Stocco, L. (2009). Notas para a interpretação das desigualdades raciais na educação. Revista Estudos Feministas, 17(3), 909-920. https://doi.org/10.1590/S0104026X2009000300019

Walsh, C. (2009). Interculturalidade crítica e pedagogia decolonial: in-surgir re-existir e re-viver. In: V. L. Candau (org). Educação intercultural na América Latina: entre concepções, tensões e propostas (pp. 11-42). Rio de Janeiro: 7Letras.

Woodward, K. (2014). Identidade e diferença: uma introdução teórica e conceitual. In: T. T. da Silva (org). Identidade e Diferença. A perspectiva dos Estudos Culturais (pp. 7-72). 15ª ed. Petrópolis, RJ: Vozes. 


\section{QUEM É NEGRA, QUEM É BRANCA, QUEM FALA, QUEM PODE FALAR: ETNOGRA- FIA DE MULHERES NEGRAS EM UMA TURMA DE FORMAÇÃO DE DOCENTES}

Resumo: Este artigo propõe uma reflexão acerca de etnografia realizada entre 2018 e 2019 em uma turma de formação de docentes de uma escola pública de Curitiba (PR). A pesquisa teve como objetivo compreender como jovens autodeclaradas negras, futuras professoras, articulavam suas identidades naquele espaço escolar. Entendemos identidades enquanto construções sociais, realizadas mediante a diferença e envolvendo disputas de legitimidade. A perspectiva que orienta a etnografia é a decolonialidade do poder-saber. No texto, é discutida a realização do trabalho etnográfico na escola, pensando os elementos que foram decisivos na aproximação com as interlocutoras. Também são debatidas as potencialidades e especificidades da etnografia na educação. Como resultado, foi possível depreender as estratégias de legitimação da identidade racial na escola; as disputas pigmentocráticas; a percepção de desconfiança e aceitação da presença da pesquisadora em campo e as reações dela provenientes, bem como a centralidade da identidade de raça/cor nesse processo.

Palavras-chave: etnografia escolar; identidades; mulheres negras; formação docente; pigmentocracia.

WHO IS BLACK, WHO IS WHITE, WHO SPEAKS, WHO CAN SPEAK: ETHNOGRAPHY OF BLACK WOMEN IN A TEACHER TRAINING CLASS

Abstract: This article proposes a reflection about an ethnography conducted between 2018 and 2019 in a teacher training class in a public school in Curitiba, state of Paraná, Brazil. The research aimed to understand how young self-declared black women, future teachers, articulated their identities in school. We understand identities as social constructions, performed through difference and involving disputes over legitimacy. The perspective that guides the ethnographic is the decoloniality of power and knowledge. In this text, we discuss the realization of ethnographic work in school, thinking about the elements that were decisive in the approximation with the interlocutors. The potentialities and characteristics of ethnography in Education are also discussed. As a result, it was possible to deduce the strategies for legitimizing racial identity in school; the pigmentocratic disputes; the perception of suspicion and acceptance of the presence of the researcher in the field, and the reactions arising from it, as well as the centrality of race/color identity in this process.

Key-words: Schooling ethnography; Identities; Black women; Teacher Education; Pigmentocracy.

RECEBIDO: $29 / 05 / 2020$

ACEITO: $11 / 05 / 2021$ 